\title{
Evaluating Resistance of Five Local Heirloom Tomato Cultivars to the Phytopathogen Fusarium oxysporum
}

\author{
Ilyaas Rhoda, Enoch A. Akinpelu, Ninon G. E. R. Etsassala and Felix Nchu*
}

\begin{abstract}
Fusarium oxysporum is a detrimental pathogen to tomatoes. It continues to present major challenges for production of tomato crops world-wide, causing extensive greenhouse and field losses. Heirloom cultivars have an expanding niche market globally. But, they are often quite susceptible to pathogens and pests. The use of resistant varieties is one of the most effective measures to control Fusarium wilt disease in the field. In this study, we tested the resistance of five tomato heirloom cultivars against fungal infection by evaluating the symptoms caused by $F$. oxysporum post-treatment. There were significant differences $(\mathrm{P} \leq 0.05)$ on plant growth (plant height) between control and fungus-exposed plants of the tomato cultivars Floradade, Moneymaker, Roma, and Large Red Cherry. Generally, exposure to the fungus was associated with reduced plant growth. Red Sweetie Cherry cultivar, on the other hand, was not significantly affected by the fungus; specifically, the fungus had limited negative effects on plant growth, leaf discolouration and disease severity. These results suggest that the Red Sweetie Cherry cultivar was relatively more resistant to the fungus compared with the other four cultivars. Red Sweetie Cherry cultivar is a potential source of resistant genes and a more suitable cultivar for cultivation in soils that are contaminated with phytopathogenic strains of $F$. oxysporum.
\end{abstract}

Keywords- Heirloom cultivars, Fusarium oxysporum, phytopathogen, tomato.

\section{INTRODUCTION}

Tomato (Solanum lycopersicum) is one of the most consumed vegetables in the world and it plays an important role in the human diet [1]. Tomato is ranked second among the most cultivated plants in the horticultural industry. Heirloom cultivars have an expanding niche market globally. Heirloom tomato cultivars are old varieties that are between $50-100$ years old. They are loved for their taste, colour and heritage. However, heirloom tomatoes are often susceptible to pests and pathogens, which cause substantial losses in tomato production [2].

Fusarium oxysporum is a major disease causing organism in tomato production; hence, various tomato cultivars are being tested to identify cultivars with the most resistance to this fungus. The fungus is widespread and occur in soils as

Manuscript received August 9, 2020. This work was supported by Cape Peninsula University of Technology, University Research Fund Grant no: R166.

I. Rhoda, E. A. Akinpelu, N. G. E. R. Etsassala and F. Nchu are with the Department of Horticultural Sciences, Cape Peninsula University of Technology, Bellville Campus, Symphony Way, PO Box 1906, Bellville, 7535, South Africa.. saprophytes; however, some of its strains can be phytopathogenic and even host specific [3]. F. oxysporum can survive for long periods of time without the presence of the host, particularly as thick-walled chlamydospores [4]. Fusarium spp. causes diseases such as Fusarium root and crown rot, as well as Fusarium wilt in tomato (Solanum lycopersicum). Currently, these pathogens are causing extensive losses to the greenhouseand field-cultivated vegetable crops, resulting in major drops in tomato yield [5]. Once a growing medium is contaminated by the pathogen, spreading of the pathogen occurs via water, wind, shoes and equipment [5]. The pathogen causes Fusarium wilt, Fusarium crown and damping off diseases to tomato seedlings. They can also cause stunting, yellowing and wilting, especially during warmer temperatures [5]. The typical wilt symptoms occur due to intense water stress, which mainly comes from vessel clogging. Wilting is commonly caused by pathogen activities, such as toxin production and accretion of fungal mycelium [4].

Chemical control is widely used for management of tomato diseases [6]. Chemical control involves the fumigation of soils using methyl bromide, captafol, chloropicrin, and thiram, among others [5]. But due to environmental issues, this approach is not deemed suitable; thus, alternative strategies are being explored, particularly biocontrol and use of resistant cultivars [3]. The first resistant tomato cultivar "Tennessee red" to fusarium wilt was released in 1912 [7]. Plant breeders in the mid 1930's used hybridization to develop more resistant varieties. Some modern cultivars have up to 12 altered disease resistant genes, which all came from wild tomato species. Breeding for multiple disease resistance typically involves broad screening of diseases.

However, new resistant races of $F$. oxysporum of well-known cultivated tomatoes have immerged over the years. This explains the serious and persistent problem posed by Fusarium wilt to tomatoes, regardless of the advancement in Fusarium resistance breeding [8]. Currently, there is no tomato cultivar that is sufficiently resistant against Fusarium wilt disease. Furthermore, the increasing market for heirloom tomatoes creates the need to assess heirloom cultivars' resistance to Fusarium wilt [9]. Heirloom seeds are passed down from generation to generation and can be traced back to the true parents. They hold interesting genes and are genetically stable making them useful to tomato breeders [10]. Therefore, the objective of this study was to investigate the susceptibility of different heirloom tomato cultivars to $F$. oxysporum. 


\section{MATERIALS AND METHODS}

\section{A. Plant Materials}

Seeds of various tomato heirloom cultivars were used for this investigation. The tomato cultivars were limited to only five different types, namely: Floradade, Moneymaker, Roma, Red Sweetie Cherry, and Large Red Cherry. The heirloom seeds were sown in 50 jiffy pellets and seeds of each cultivar were planted. The jiffy pellets were made from sphagnum peat combined with lime and a special fertilizer, which acted as a substrate.

\section{B. Fungal Culture}

Clean cultures of $F$. oxysporum that were previously isolated from maize and are currently being maintained in the Department of Horticulture Research Laboratory, CPUT, were used. The fungus was cultured on a half strength selective medium of Potato Dextrose Agar (PDA) which contained $0.04 \mathrm{~g} / \mathrm{L}$ of streptomycin and $0.02 \mathrm{~g} / \mathrm{L}$ ampicillin. The media was placed in $9 \mathrm{~cm}$ diameter Petri dishes and incubated at $26^{\circ} \mathrm{C}$ for a period of four weeks (28 days). Conidia were gently scraped-off the surface of the petri dishes and suspended into a $500 \mathrm{ml}$ beaker of sterile water containing $0.05 \%$ Tween 80 . The beaker was then placed on a magnetic mixer for 30 minutes at 20 ${ }^{\circ} \mathrm{C}$ and $300 \mathrm{rpm}$ to homogenize the conidial suspension. A haemocytometer and a light microscope at magnification $400 \mathrm{X}$ were used to enumerate the conidia concentration of $1 \times 10^{6}$ conidia $\mathrm{ml}^{-1}[11]$.

\section{Experimental Procedures}

The experiment was carried out in the glasshouse, of the Department of Horticultural Sciences, Bellville campus, CPUT. This experiment was based on a randomised block design. The plants were randomly selected and allocated into two treatments: a test treatment whereby plants were inoculated with a fungal suspension at the concentration of $1 \times 10^{6}$ conidia ml ${ }^{-1}$ in $0.05 \%$ Tween 80 and a control treatment where the plants were served with sterilized water mixed with $0.05 \%$ Tween 80 . To inoculate, plants $(n=50)$ were randomly selected at $10-12$ weeks old, where plants $(n=5)$ of each cultivar (Floradade, Moneymaker, Roma, Red Sweetie Cherry, Large Red Cherry) roots were individually submerged in a conidial suspension at a concentration of $1 \times 10^{6}$ conidia ml ${ }^{-1}$ for 24 hours. The 25 control plants' roots were submerged in sterilized water mixed with $0.05 \%$ of Tween 80 . The 50 plants were transplanted into pots containing a substrate mix of equal parts potting soil, sphagnum peat moss, perlite and compost. The experimental plants were drenched every second day with the $100 \mathrm{ml}$ of the conidial suspension or control $(0.05 \%$ of Tween 80$)$. In addition, a hydroponics fertilizer (Nutrifeed) (Starke Ayres Pty Ltd, Cape Town) was added as a soil drench to enhance plant growth. The fertilizer contained the following ingredients: $\mathrm{N}$ (65000 mg kg-1), P (27000 mg kg-1), K (130000 mg kg-1), Ca $\left(70 \mathrm{mg} \mathrm{kg}^{-1}\right), \mathrm{Cu}\left(20 \mathrm{mg} \mathrm{kg}^{-1}\right), \mathrm{Fe}\left(1500 \mathrm{mg} \mathrm{kg}^{-1}\right)$, Mo (10 mg $\left.\mathrm{kg}^{-1}\right), \mathrm{Mg}\left(22 \mathrm{mg} \mathrm{kg}^{-1}\right), \mathrm{Mn}\left(240 \mathrm{mg} \mathrm{kg}^{-1}\right), \mathrm{S}\left(75 \mathrm{mg} \mathrm{kg}^{-1}\right), \mathrm{B}$ $\left(240 \mathrm{mg} \mathrm{kg}^{-1}\right)$ and $\mathrm{Zn}\left(240 \mathrm{mg} \mathrm{kg}^{-1}\right)$. The nutrient solution was formulated at a concentration of $5 \mathrm{~g} / 5 \mathrm{~L}$. The plants were maintained in the greenhouse under the following conditions: 25 $\pm 2{ }^{\circ} \mathrm{C}$, relative humidity of $70 \% \mathrm{RH}$.

The data on plant growth (height in $\mathrm{cm}$ ), leaf colour and disease severity were recorded at two weeks' post-treatment. The plant height was measured from the surface of the medium to the tip of the plant using a tape measure. Data on nitrogen needs of experimental plants was recorded by observing the leaf colour intensity on a scale of $1-4$, corresponding to the leaf colour chart (LCC) values [12]. The levels of the LCC ranged from: LCC level 1 (Yellowish Green), LCC level 2 (Light Green), LCC level 3 (Green), LCC level 4 (Dark Green). The levels of disease severity, based on a scale of $1-5$, was recorded as previously described by Cai et al [13]: 1 - death, 2 severe wilting or stunting, 3 - moderate wilting or stunting, 4 slight wilting or stunting, 5 - No Symptom.

\section{Statistical Analysis}

The experimental data for plant height, leaf colour and disease severity were analysed using One-way ANOVA. The means were separated using a post-hoc Turkey test. Graphs and tables were compiled on Microsoft Excel 2018.

\section{RESULTS}

Generally, $F$. oxysporum affected plant growth in all cultivars. However, besides Red Sweetie Cherry, significantly lower plants heights were observed among the plants of the other four cultivars (Floradade, Moneymaker, Roma, and Large Red Cherry) compared to the corresponding control treatments (Fig. 1). The highest suppression of growth in terms of height were observed in Floradade and Moneymaker, which recorded $14.2 \mathrm{~cm}$ and $30 \mathrm{~cm}$ in fungus treated plants compared to their corresponding control counterparts $27.6 \mathrm{~cm}$ and $41 \mathrm{~cm}$, respectively.

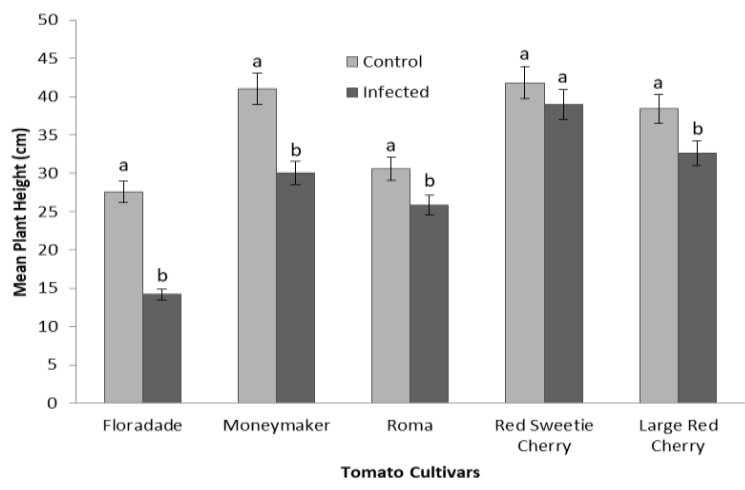

Fig. 1. Mean plant height $(\mathrm{cm})$ of various tomato cultivars after experimental infection with $F$. oxysporum. Means with the lower case letter 'a' are not significantly different and means with the lower case letter ' $b$ ' are significantly different in terms of the mean value $(\mathrm{P} \leq 0.05)$.

Similarly, there were significant differences $(\mathrm{P} \leq 0.05)$ in tomato cultivar's leaf colour (Floradade, Moneymaker, Roma and Large Red Cherry), whereas Red Sweetie Cherry cultivar presented no significant difference $(\mathrm{P} \geq 0.05)$ with only minor changes in leaf colour - Fig. 2. 


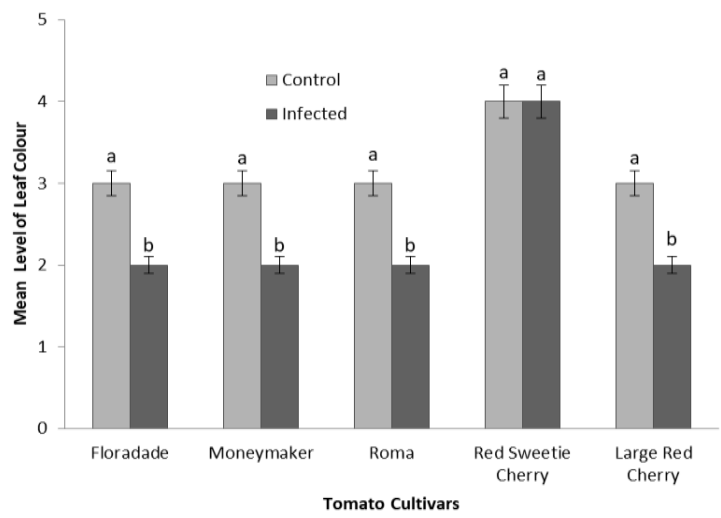

Fig. 2. Mean level of leaf colour based on LCC of various tomato cultivars after infection. Means with the same lower case letter are not significantly different between control- and fungus-treated plants at $\mathrm{P} \leq 0.05$. ( $1=$ Yellowish Green, $2=$ Light green, 3= Green, 4= Dark Green)

On the level of wilt severity, Floradade cultivar was the most significantly affected, having a mean severity scale of 2.6, while the Red Sweetie Cherry, with 4.6, was the least affected by the $F$. oxysporum. The overall difference in diseases severity was statistically significant when fungus treated plants of the different cultivars were compared $(\mathrm{P}=0.003 ; \mathrm{df}=4,20 ; \mathrm{F}=5.5)$ see Table I.

TABLE I: STATISTICAL ANALYSIS OF SEVERITY OF DISEASE ON TOMATO

\begin{tabular}{|c|c|c|c|c|c|}
\hline \multicolumn{6}{|c|}{ CULTIVARS } \\
\hline & & Mean & Standard & $\mathrm{dF}$ & $\mathrm{P}(\mathrm{T}<=\mathrm{t})$ \\
\hline & & & Error & & two-tail \\
\hline \multirow[t]{2}{*}{ Floradade } & $\mathrm{C}$ & 4.8 & 0.2 & \multirow[t]{2}{*}{8} & \multirow[t]{2}{*}{0.0001} \\
\hline & I & 2.6 & 0.2 & & \\
\hline \multirow[t]{2}{*}{ Moneymaker } & $\mathrm{C}$ & 4.8 & 0.2 & \multirow[t]{2}{*}{8} & \multirow[t]{2}{*}{0.008} \\
\hline & I & 3.8 & 0.2 & & \\
\hline \multirow[t]{2}{*}{ Roma } & $\mathrm{C}$ & 4.8 & 0.2 & \multirow[t]{2}{*}{8} & \multirow[t]{2}{*}{0.014} \\
\hline & I & 3.4 & 0.4 & & \\
\hline Red Sweetie & $\mathrm{C}$ & 4.8 & 0.2 & \multirow[t]{2}{*}{8} & \multirow[t]{2}{*}{0.545} \\
\hline Cherry & I & 4.6 & 0.2 & & \\
\hline Large Red & $\mathrm{C}$ & 4.8 & 0.2 & \multirow[t]{2}{*}{8} & \multirow[t]{2}{*}{0.014} \\
\hline Cherry & I & 3.4 & 0.4 & & \\
\hline
\end{tabular}

*Disease severity: 1 = Death; 2 = Severe Wilting or Stunting; 3 = Moderate Wilting or Stunting; 4 = Slight Wilting or Stunting; $5=$ No Symptom; $C=$ control; I= infected

Regarding the average level of disease severity, (Table I) there were significant differences of tomato cultivars (Floradade, Moneymaker, Roma and Large Red Cherry). Wilt, blight and discoloration shown in Figure 3 are some of the symptoms observed in this study
(A)

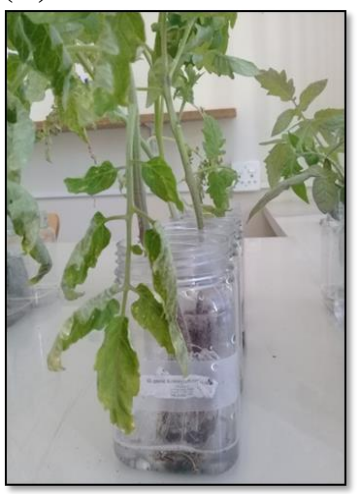

(B)

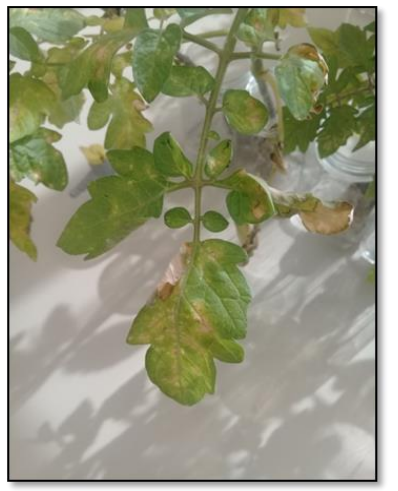

Fig. 3. A) Plant submerged in conidial suspension showing leaves are starting to wilt, B) plant leaves with blight and discoloration symptoms caused by $F$. oxysporum from 7 days' post-treatment.

\section{DISCUSSION}

This study confirmed that susceptibility of heirloom tomatoes to $F$. oxysporum varied among cultivars and revealed that Floradade was the most susceptible cultivar while Red Sweetie Cherry was the most resistant cultivar. Exposure of plants to $F$. oxysporum led to decreases in plant height as well as observable change in colour in all cultivars of tomatoes. However, of the five cultivars tested, Red Sweetie Cherry was the only cultivar whose growth was not significantly affected by the fungus. Interestingly, Red Sweetie Cherry recorded the least wilt severity when cultivated in the presence of the fungus compared to the other cultivars.

The wilt symptoms, generally, occur in the plants because of incursion and obstruction of discrete zones of the vascular tissue by the fungus [5]. F. oxysporum is one the most damaging diseases of tomato plants, where the fungus settles in the host plant and causes breakdown and blockage of the xylem which leads to disease symptoms [14].

In the present study, Floradade cultivar was the most susceptible to the fungus, whereas Red Sweetie Cherry was most resistant to the fungus infection. Previous studies have reported variations of resistance and/or susceptibility of cultivars of tomatoes to Fusarium oxysporum [15-17]. Bonny Best cultivar was completely susceptible while Marglobe and Rutgers cultivars of tomato were resistance to the $F$. oxysporum [15]. Fusaric acid toxin produced by the $F$. oxysporum is known to cause wilt disease in tomato crop [18]. Future studies should analyse the content of fusaric acid, secondary metabolites and protein contents in the different cultivars of tomatoes to better understand the physiological responses of cultivars to the pathogens.

\section{CONCLUSION}

In this study, Red Sweetie Cherry cultivar was the most effective against the pathogen and could be an important source of resistant genes against the fungus. 


\section{ACKNOWLEDGMENT}

The authors would like to thank Timothy Jasson, Shaheed Roos and Christiaan Daniels of the Department of Horticultural Sciences, CPUT for the review and technical support during the laboratory and the greenhouse experiments.

\section{REFERENCES}

[1] A. Manaa, E. Gharbi, H. Mimouni, S. Wasti, S. Aschi-Smiti, S. Lutts, and H. B. Ahmed, "Simultaneous application of salicylic acid and calcium improves salt tolerance in two contrasting tomato (Solanum lycopersicum) cultivars," South African Journal of Botany, vol. 95, pp. 32-39, 2014. https://doi.org/10.1016/j.sajb.2014.07.015

[2] N. Ozbay, and S. E. Newman, "Fusarium crown and root rot of tomato and control methods," Plant Pathology Journal, vol. 3, no. 1, pp. 9-18, 2004. https://doi.org/10.3923/ppj.2004.9.18

[3] Y. Panina, D. Fravel, C. Baker, and L. Shcherbakova, "Biocontrol and plant pathogenic Fusarium oxysporum induced changes in phenolic compounds in tomato leaves and roots," Journal of Phytopathology, vol. 155 , no. 7-8, pp. 475-481, 2007 https://doi.org/10.1111/j.1439-0434.2007.01260.x

[4] A. D. Pietro, M. P. Madrid, Z. Caracuel, J. Delgado-Jarana, and M. I. G. Roncero, "Fusarium oxysporum: exploring the molecular arsenal of a vascular wilt fungus," Molecular plant pathology, vol. 4, no. 5, pp. $315-325,2003$ https://doi.org/10.1046/j.1364-3703.2003.00180.x

[5] R. McGovern, "Management of tomato diseases caused by Fusarium oxysporum," Crop Protection, vol. 73, pp. 78-92, 2015. https://doi.org/10.1016/j.cropro.2015.02.021

[6] J. Amini, and D. Sidovich, "The effects of fungicides on Fusarium oxysporum f. sp. lycopersici associated with Fusarium wilt of tomato," Journal of plant protection research, vol. 50, no. 2, pp. 172-178, 2010. https://doi.org/10.2478/v10045-010-0029-x

[7] G. Bauchet, and M. Causse, "Genetic diversity in tomato (Solanum lycopersicum) and its wild relatives," Genetic diversity in plants, vol. 8, pp. 134-162, 2012. https://doi.org/10.5772/33073

[8] A. De Cal, R. Garcia-Lepe, and P. Melgarejo, "Induced resistance by Penicillium oxalicum against Fusarium oxysporum f. sp. lycopersici: histological studies of infected and induced tomato stems," Phytopathology, vol. 90, no. 3, pp. 260-268, 2000. https://doi.org/10.1094/PHYTO.2000.90.3.260

[9] C. Borrero, M. I. Trillas, J. Ordovás, J. C. Tello, and M. Avilés, "Predictive factors for the suppression of Fusarium wilt of tomato in plant growth media," Phytopathology, vol. 94, no. 10, pp. 1094-1101, 2004. https://doi.org/10.1094/PHYTO.2004.94.10.1094

[10] L. Ayre. "Vegetable Gardening with Lorraine," 29 April, 2019; http://www.vegetable-gardening-with-lorraine.com/heirloom-seeds.html

[11] S. Moloinyane, and F. Nchu, "The effects of endophytic Beauveria bassiana inoculation on infestation level of Planococcus ficus, growth and volatile constituents of potted greenhouse grapevine (Vitis vinifera L.)," Toxins, vol. 11, no. 2, pp. 72, 2019. https://doi.org/10.3390/toxins11020072

[12] T. Fairhurst, C. Witt, R. Buresh, A. Dobermann, and T. Fairhurst, Rice: A practical guide to nutrient management: Int. Rice Res. Inst., 2007.

[13] G. Cai, L. R. Gale, R. Schneider, H. Kistler, R. Davis, K. Elias, and E. Miyao, "Origin of race 3 of Fusarium oxysporum f. sp. lycopersici at a single site in California," Phytopathology, vol. 93, no. 8, pp. 1014-1022, 2003. https://doi.org/10.1094/PHYTO.2003.93.8.1014

[14] A. K. Ramaiah, and R. K. H. Garampalli, "In vitro antifungal activity of some plant extracts against Fusarium oxysporum f. sp. lycopersici," Asian Journal of Plant Science and Research, vol. 5, no. 1, pp. 22-27, 2015.

[15] R. P. Larkin, and D. R. Fravel, "Effects of varying environmental conditions on biological control of Fusarium wilt of tomato by nonpathogenic Fusarium spp," Phytopathology, vol. 92, no. 11, pp. 1160-1166, 2002.

https://doi.org/10.1094/PHYTO.2002.92.11.1160
[16] G. Abawi, and K. Barker, "Effects of cultivar, soil temperature, and population levels of Meloidogyne incognita on root necrosis and Fusarium wilt of tomatoes," Phytopathology, vol. 74, no. 4, pp. 433-438, 1984. https://doi.org/10.1094/Phyto-74-433

[17] B. Cwalina-Ambroziak, and R. Amarowicz, "Effects of Biological and Fungicidal Environmental Protection on Chemical Composition of Tomato and Red Pepper Fruits," Polish Journal of Environmental Studies, vol. 21, no. 4, 2012.

[18] I. Gapillout, M.-L. Milat, and J.-P. Blein, "Effects of fusaric acid on cells from tomato cultivars resistant or susceptible to Fusarium oxysporum f. sp. Lycopersici," European journal of plant pathology, vol. 102, no. 2, pp. 127-132, 1996.

https://doi.org/10.1007/BF01877099

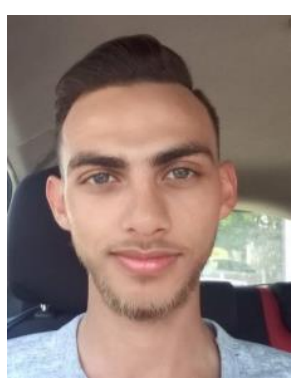

Ilyaas Rhoda was born on the 17.06.1997 in Cape Town, Western Cape, South Africa. His secondary education took place in Strand, Cape Town, South Africa, where he attained his Matric Certificate at Madrasatur Rajaa High School in 2015. He studied at the Cape Peninsula University of Technology in Bellville, Cape Town, South Africa, where he achieved the following qualifications, National Diploma (2018), BTech degree (2019) in Horticulture, respectively. Ilyaas Rhoda's field is mainly focused on biological plant protection against destructive micro-organisms and pests. He did his Student Internship at the Western Cape Government, Department of Transport and Public Works in 2018. 